\title{
ESTUDO POR DOCAGEM MOLECULAR DE INIBIDORES DA ENZIMA GSK-3ß: UMA PROPOSTA PARA O TRATAMENTO DO TRANSTORNO BIPOLAR
}

\author{
STUDY BY MOLECULAR DOCKING OF INHIBITORS OF THE ENZYME \\ GSK-3ß: A PROPOSAL FOR THE TREATMENT OF THE BIPOLAR \\ DISORDER
}

\author{
Edilson Galdino Santos Silva Júnior ${ }^{1}$ \\ Arlan da Silva Gonçalves $1,2,3 *$
}

\begin{abstract}
${ }^{1}$ Instituto Federal do Espírito Santo -Campus Vila Velha; ${ }^{2}$ Instituto Federal do Espírito Santo - Programa de Pós-Graduação em Tecnologias Sustentáveis (PPGTECS), unidade Vitória - ES - Brazil 3 Universidade Federal do Espírito Santo, Programa de Pós-Graduação em Química (PPGQUI),

Vitória - ES - Brazil

*Autor para correspondência: agoncalves@gmail.com
\end{abstract}

Artigo submetido em 23/10/2018, aceito em 09/05/2019 e publicado em 15/08/2019.

Resumo: Neste trabalho foram utilizadas técnicas de docagem molecular (molecular docking) para simular, in silico, a interação entre inibidores alternativos e a glicogênio sintase quinase 3 beta (GSK$3 \beta$ ), enzima associada ao transtorno bipolar do humor. Os resultados permitiram a análise da energia desprendida no processo de inibição entre a enzima e os inibidores, além do estudo das principais interações realizadas nos complexos receptor-ligante formados.

Palavras-chave: docagem molecular; transtorno bipolar; fármacos; GSK-3 $\beta$.

\begin{abstract}
In this work, molecular docking techniques were used to simulate, in silico, the interaction between alternative inhibitors and glycogen synthase kinase 3 beta (GSK-3 $\beta$ ), an enzyme associated to mood bipolar disorder. The results allowed the analysis of the energy released in the process of inhibition between the enzyme and the inhibitors, in addition to the study the main interactions carried out on the receptor-ligand complexes formed.
\end{abstract}

Keywords: molecular docking; bipolar disorder; drugs; GSK-3 $\beta$. 


\section{INTRODUÇÃO}

O transtorno bipolar do humor $(\mathrm{TBH})$ é uma condição crônica caracterizada por episódios alternados de humor que abrangem principalmente episódios de mania e depressão maior, e que podem causar um grande número de consequências psicossociais como problemas nos relacionamentos interpessoais e envolvimento em situações de risco, incluindo suicídio, homicídio e acidentes (DEL PORTO e VERSIANI, 2005).

$$
\text { Dentre os principais }
$$
medicamentos utilizados para o controle dessa enfermidade, estão os medicamentos à base de lítio, como o carbonato de lítio, que foi o primeiro estabilizador de humor utilizado no $\mathrm{TBH}$, tendo sua comercialização iniciada a partir da década de 70 e tornando-se o medicamento de escolha utilizado no tratamento do transtorno (ROSA et al, 2006).

Entre as principais funções do lítio, destacam-se suas propriedades antisuicidas e o fato de impedir que um paciente eutímico entre em novos episódios afetivos (NEWMAN et al, 2006). Apesar da sua eficiência, a dificuldade de adesão terapêutica ao lítio chega a ser um problema no tratamento do transtorno, apresentando taxas de até $50 \%$ de não adesão, devido principalmente a fatores sociodemográficos, e a fatores relacionados à postura perante a enfermidade. (CASTRO-COSTA e SILVA, 2011)

Além da adesão ao lítio, existem preocupações relacionadas com a própria prescrição do medicamento, tais como o fato de o lítio ter uma janela terapêutica estreita, a exigência de coletas frequentes para verificação dos níveis séricos, a toxicidade renal causada pelas medicações com base em lítio particularmente com o uso a longo prazo, que incluem prejuízos à função tabular e doença renal crônica progressiva - e diabetes insipidus nefrogênico, distúrbio no qual os rins não conseguem reter a água filtrada adequadamente, e acomete até $40 \%$ dos pacientes nas primeiras semanas do tratamento. (OLIVEIRA et al, 2010; APHRAMIAN, 2013).

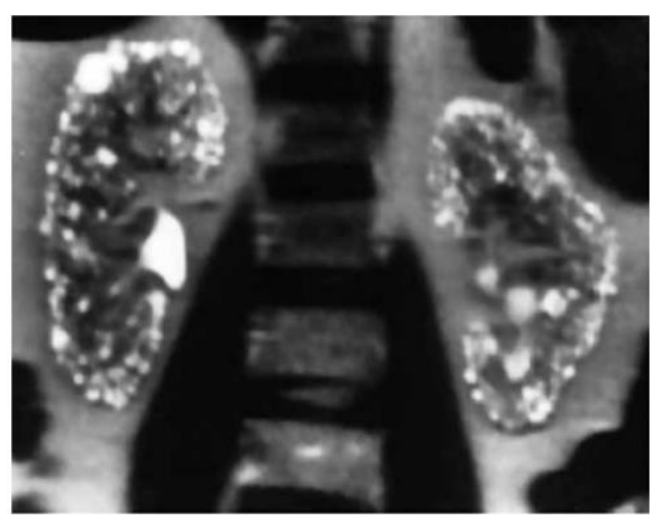

Figura 1 - Microcistos nas regiões cortical e medular de ambos rins de um paciente de 68 anos, mostrados em ressonância magnética (TIMMER, 1999).

Uma possível razão para tais efeitos encontra-se na capacidade do lítio em substituir o sódio ou o potássio em proteínas de transporte, proporcionando um caminho para a entrada de lítio nas células e o consequente um acúmulo intracelular, já que as vias para o transporte de lítio para fora das células são mais limitadas (TIMMER, 1999).

Atualmente, sabe-se que a resposta ao tratamento do transtorno bipolar com sais de lítio é influenciada pela inibição da isoenzima glicogênio sintase kinase $3 \beta$ (GSK-3 $\beta$ ) promovida por este cátion, e apesar de sua eficiência terapêutica, é necessário uma concentração relativamente alta de lítio para inibição da GSK-3 $\beta$, já que seu IC50 (concentração necessária para inibir cinquenta por cento da população enzimática) está na faixa entre 1 a 2 milimolar, sugerindo uma concentração elevada desse cátion para inibição da isoenzima (KLEIN e MELTON, 1996; ELDAR-FINKELMAN, 2002). 
Com base no que foi explicitado acima, neste trabalho foram empregadas técnicas de docagem molecular (do inglês: molecular docking) para se ter uma noção mais precisa dos tipos de interação receptor-ligante entre a enzima GSK-3 $\beta$ e diferentes tipos de inibidores emergentes, assim como a tendência desses compostos químicos em inibir a GSK-3 $\beta$, possibilitando o planejamento

\section{MATERIAS E MÉTODOS}

A docagem molecular, técnica utilizada neste trabalho, é um método in silico no qual prediz a orientação de uma molécula em relação a uma segunda, quando ligadas uma a outra para formar um complexo receptor-ligante estável (MUKESH; RAKESH, 2011).

A Figura 2 representa de forma simplificada o processo de docagem de fármacos mais promissores para $\mathrm{o}$ tratamento do TBH. molecular, onde a figura maior, de cor azul-claro, representa um receptor e as figuras menores são os ligantes que nele se complexam. No final da docagem, tem-se os complexos receptor-ligante formados e a energia desprendida no processo.

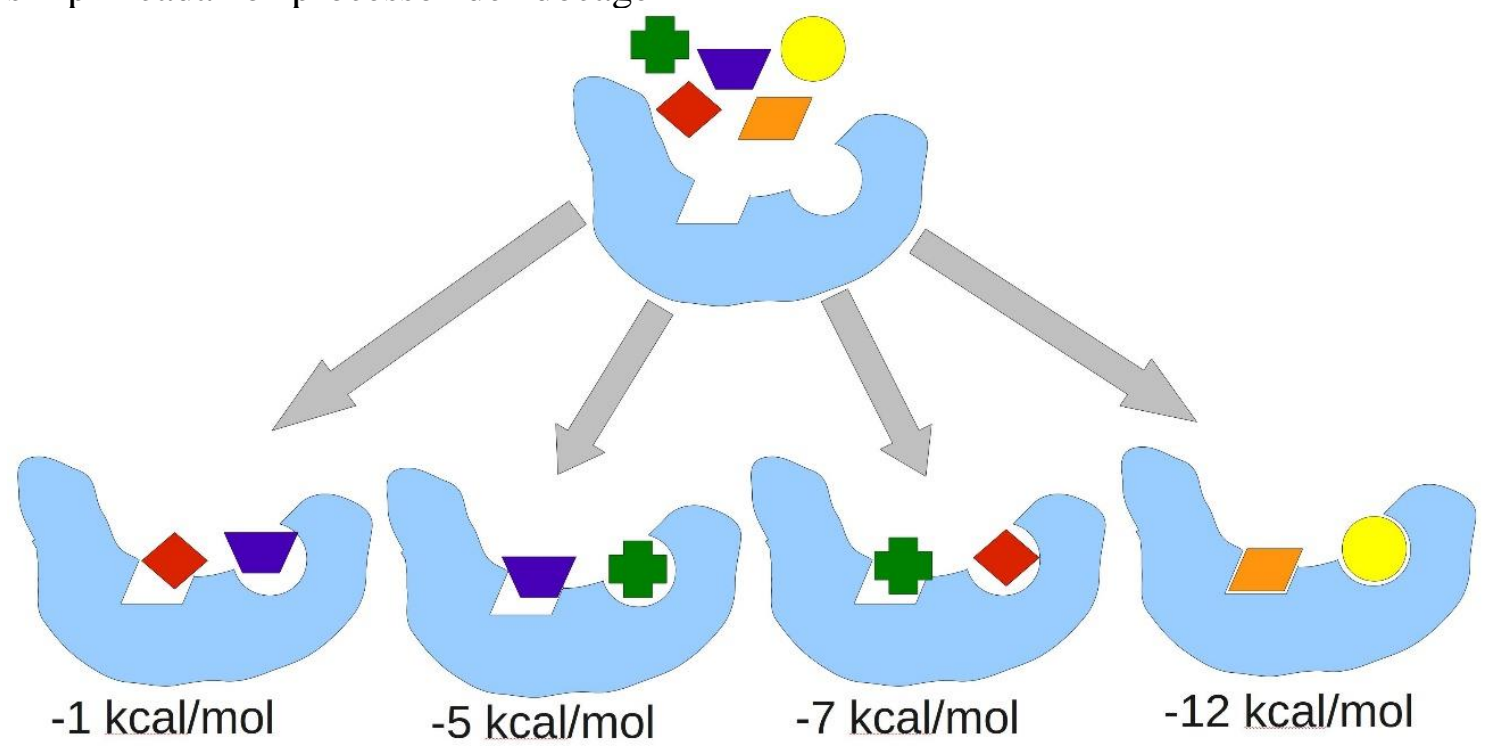

Figura 2 - Representação simplificada da docagem molecular (PIETRALONGA et al, 2015).

Atualmente, muitos grupos de compostos químicos de origens diversas emergiram como potenciais inibidores da GSK-3 $\beta$. Neste trabalho foram utilizados, para docagem molecular com a GSK-3 $\beta$, inibidores já testados em sistemas biológicos. Abaixo estão o conjunto de moléculas utilizadas, que diferem quanto a sua origem (grupo A: isoladas de organismos marinhos e grupo B: sintéticas) (ELDAR-FINKELMAN e MARTINEZ, 2011). 
Grupo A

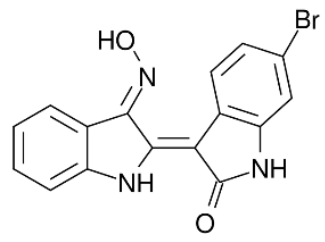

6-BIO

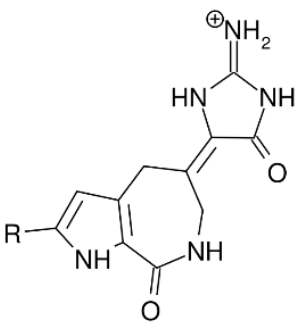

$\mathrm{R}=\mathrm{Br}$ Hymenialdisine $\mathrm{R}=\mathrm{H}$ Debromohymenialdisine

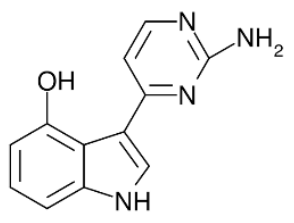

Meridianine A

Grupo B<smiles>[R]c1ccc([R6]([H])([H])[O-])cc1</smiles><smiles>COc1cn(-c2cnc(NCCNc3ccc(C#N)cn3)nc2-c2ccc(Cl)cc2Cl)cn1</smiles>
$\mathrm{R}=\mathrm{H}$ CHIR98023 CHIR99021

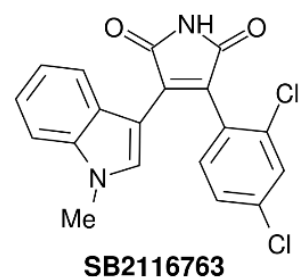<smiles>O=C1NC(=O)C(c2ccccc2[N+](=O)[O-])=C1Nc1ccc(O)c(Cl)c1</smiles><smiles></smiles>

SB415286

$\mathrm{R}=\mathrm{Br} \mathrm{X}=\mathrm{CHKenpaullone}$ $\mathrm{R}=\mathrm{CN} X=$ NCazpaullone $\mathrm{R}=\mathrm{NO}_{2} \mathrm{X}=\mathrm{CH}$ Alsterpaullone<smiles>COc1ccc(CNC(=O)Nc2ncc([N+](=O)[O-])s2)cc1</smiles><smiles>Nc1cccc(-c2cc3c(Oc4cccc(O)c4)ncnc3[nH]2)c1</smiles>

Figura 3 - Conjunto de moléculas utilizadas neste trabalho (Adaptado de ELDARFINKELMAN e MARTINEZ, 2011).

Para o preparo da docagem, tais moléculas foram primeiramente desenhadas e analisadas em $\mathrm{pH}$ biológico $(7,4)$, utilizando o software MARVIN, a fim de se conhecer os estados de protonação das mesmas. Após a determinação dos estados de protonação, as moléculas foram redesenhadas, com seus devidos estados de protonação, e otimizadas (colocá-las geometricamente estáveis, com os valores dos comprimentos das ligações e os ângulos entre os átomos próximos dos valores experimentais) utilizando $\mathrm{o}$ GHEMICAL, que é um programa gratuito e fácil de utilizar (HASSINEN e PERAKYLA, 2001).

As moléculas então foram otimizadas semi-empiricamente usando o método PM7, com o programa MOPAC e suas cargas foram adicionadas pelo software CHIMERA, utilizando o método AM1-BCC (STEWART, 2007).

Após essas etapas, as moléculas foram salvas em formato .mol2, que 
contém informações sobre as coordenadas de cada átomo, além dos valores das cargas atômicas, informações úteis para o cálculo de docagem molecular (PIETRALONGA et al, 2015).

A estrutura cristalográfica da GSK-3 $\beta$, de código 1gng, utilizado para a docagem foi descarregado, em formado PDB, da database www.rcsb.org, onde foi obtido através de cristalografia e difração de raio $x$ (ELDARFINKELMAN e MARTINEZ, 2011).

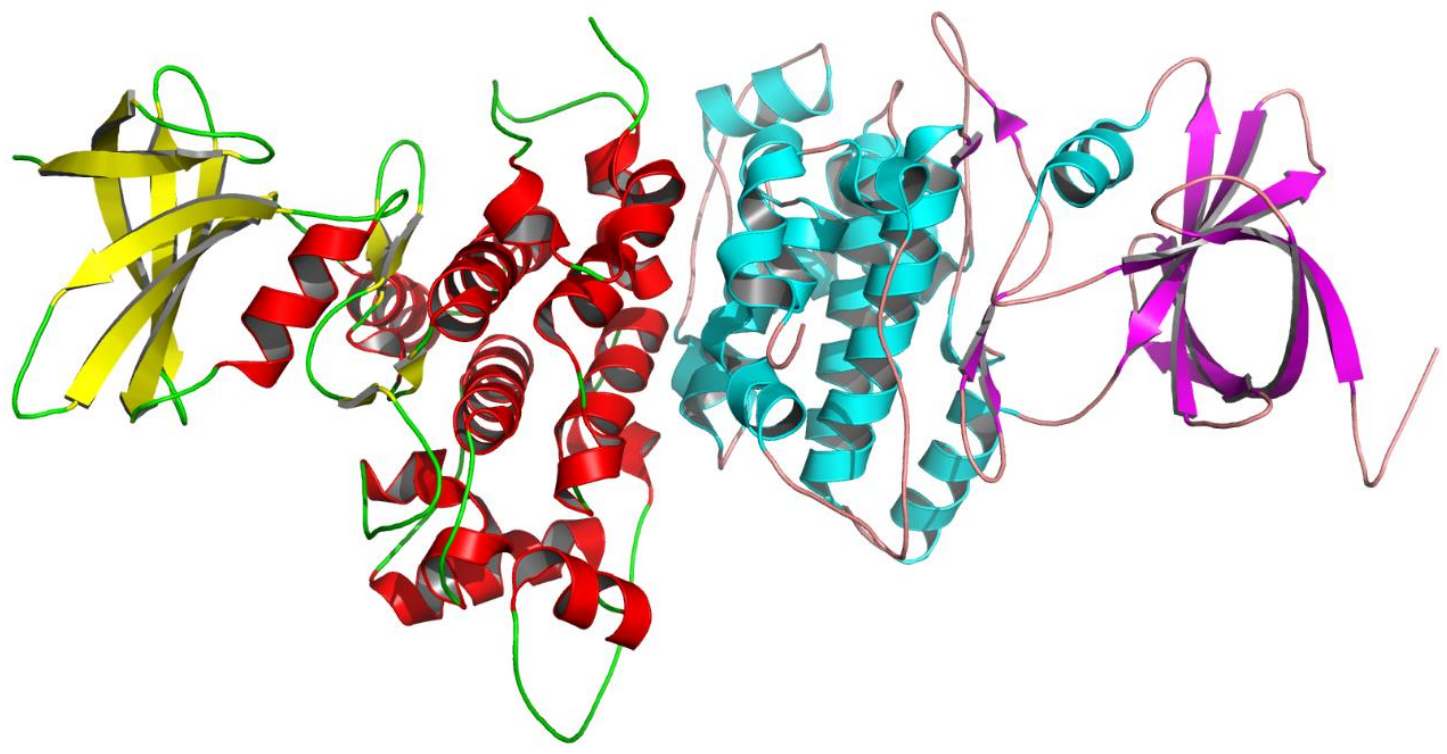

Como a GSK-3 $\beta$ é um dímero, constituído por duas grandes regiões idênticas, foi selecionada apenas uma cadeia para simulação devido à simetria entre elas. Os ligantes testados nesse trabalho são competitivos com o sítio ativo no qual a enzima se complexa com o ATP. Essa região compreende os aminoácidos Phe67, Lys85, Glu97,
Arg141, Gln185, Asp200 e Arg220. Porém, nesse trabalho optou-se em definir uma região no espaço (grid) que abrangesse todo monômero selecionado, devido à possibilidade de complexação dos ligantes em um outro possível sítio ativo da GSK-3 $\beta$ (ELDARFINKELMAN e MARTINEZ, 2011). 


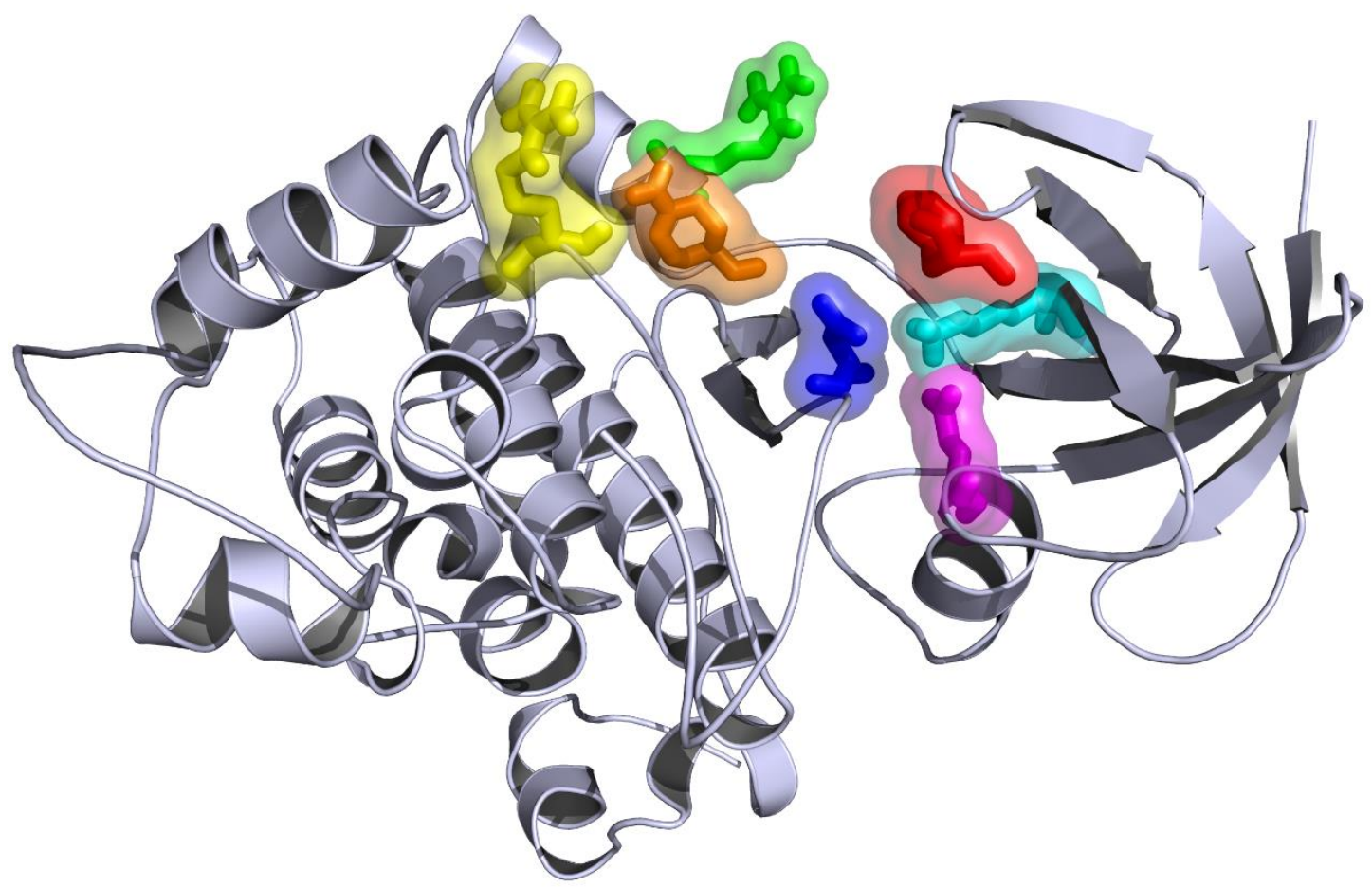

Figura 5 - Aminoácidos de interação entre a GSK-3 $\beta$ e os inibidores em estudo Phe67 (Vermelho), Lys85 (Ciano), Glu97 (Magenta), Arg141 (Verde), Gln185 (Laranja), Asp200 (Azul) e Arg220 (Amarelo).

Após o preparo das moléculas (ligantes) e da enzima (receptor), é então realizado a docagem molecular. A abordagem mais comumente utilizada na docagem, e também a utilizada neste trabalho, é a flexible-ligand docking, onde os ligantes são flexíveis enquanto o receptor é rígido (DHANIK e KAVRAKI, 2012).

Em relação à energia de docagem (Edocking), que prediz informações sobre a afinidade de ligação, quanto menor, melhor será a docagem molecular, sendo tal energia definida pela equação:

$$
\mathrm{E}_{\text {docking }}=\mathrm{E}_{\text {inter }}+\mathrm{E}_{\text {intra }}
$$

Onde o primeiro termo dessa equação $\left(E_{\text {inter }}\right)$ se refere à energia de interação entre o receptor e o ligante, e é baseada nas interações de van Der Waals e interações eletrostáticas, e o segundo termo da equação $\left(E_{\text {intra }}\right)$ se relaciona principalmente com os graus de liberdade do ligante (PIETRALONGA et al, 2015).

No final da docagem molecular tem-se o complexo receptor-ligante formado, assim como as principais interações entre o ligante e o receptor e a energia de docking envolvida no processo, que se correlaciona com a constante de inibição, a partir da seguinte dedução:

$\mathrm{O}$ equilíbrio do complexo receptorligante pode ser expressado como:

$$
\mathrm{E}+\mathrm{I} \leftrightarrow \mathrm{EI}
$$

Onde E (enzima) se refere ao receptor e I (inibidor) ao ligante. A expressão para a constante de associação $(\mathrm{Ka})$ do ligante ao receptor é dada por:

$$
\mathrm{Ka}=\frac{[\mathrm{EI}]}{[\mathrm{I}][\mathrm{E}]}(2)
$$

A constante de dissociação $(\mathrm{Kd})$ é 
definida como o inverso de $\mathrm{Ka}$, medindo a propensão do ligante em se dissociar do receptor, assim como a constante de inibição (Ki):

$$
\mathrm{Ka}=\frac{[\mathrm{EI}]}{[\mathrm{I}][\mathrm{E}]}=\frac{1}{\mathrm{Kd}}=\frac{1}{\mathrm{Ki}}(3)
$$

Então:

$$
\begin{array}{r}
\mathrm{Ki}=\frac{[\mathrm{I}][\mathrm{E}]}{[\mathrm{EI}]}(4) \\
\mathrm{Ki}=\frac{1}{\mathrm{Ka}}(5)
\end{array}
$$

Ao aplicar o logaritmo neperiano,

$$
\ln \mathrm{Ka}=-\ln \mathrm{Ki}(6)
$$

E da termodinâmica, tem-se que:

$$
\begin{gathered}
\Delta \mathrm{G}=-\mathrm{RT} \times \ln \mathrm{Ka}(7) \\
\Delta \mathrm{G}=\mathrm{RT} \times \ln \mathrm{Ki}(8)
\end{gathered}
$$

Como a constante de associação e a constante de inibição ocorrem em sentidos opostos, remove-se o sinal negativo, assim:

\section{RESULTADOS E DISCUSSÃO}

Após a etapa de atracamento molecular, a constante de inibição dos complexos receptor-ligante foi determinada através da energia de docking utilizando a equação (1), a

$$
\ln \mathrm{Ki}=\frac{\Delta \mathrm{G}}{\mathrm{RT}}(9)
$$

E ao aplicar a exponencial em ambos lados, tem-se:

$$
K i=e^{\left(\frac{\Delta G_{\text {binding }}}{R \cdot T}\right)}
$$

Equação 10 - Relação de $\mathrm{Ki}$ com a energia livre de ligação.

Quanto menor Ki (ou Kd), maior a afinidade de ligação e menor a concentração do fármaco necessária para inibir a atividade da enzima. A partir daí, a energia livre de ligação, que se correlaciona com a constante de inibição, através da equação 1 , foi determinada neste trabalho, além do estudo das principais interações, que também foram determinadas e visualizadas, em nível molecular.

tabela abaixo resume os valores de $\mathrm{Ki}$ para cada ligante, assim como a energia de ligação e o $\mathrm{IC}_{50}$ dos mesmos, que expressa a metade da concentração inibitória máxima.

Tabela 1 - Energia de ligação, constante de inibição e $\mathrm{IC}_{50}$ dos ligantes.

\begin{tabular}{c|c|c|c}
\hline Ligante & Energia de ligação (kcal/mol) & KI $(\boldsymbol{\mu M})$ & IC $\mathbf{5 0}(\boldsymbol{\mu M})$ \\
\hline Meridianine-A (a) & $-6,3$ & 36,2 & - \\
Debrohymendialsine(b) & -7.9 & 2,7 & - \\
SB415286 (c) & -7.2 & 8,4 & - \\
Alsterpaullone(d) & $-8,3$ & 1,4 & $4 \times 10^{-3}-0,08$
\end{tabular}




\begin{tabular}{|c|c|c|c|}
\hline Kenpaullone (e) & $-8,3$ & 1,4 & $4 \times 10^{-3}-0,08$ \\
\hline Cazpaullone (f) & $-8,2$ & 1,7 & $4 \times 10^{-3}-0,08$ \\
\hline CHIR98014 (g) & $-7,7$ & 3,7 & $6 \times 10^{-5}-7 \times 10^{-3}$ \\
\hline CHIR98023 (h) & $-7,7$ & 3,7 & $6 \times 10^{-5}-7 \times 10^{-3}$ \\
\hline CHIR99021 (i) & $-7,3$ & 7,1 & $6 \times 10^{-5}-7 \times 10^{-3}$ \\
\hline TWS119 (j) & $-8,0$ & 2,3 & $6 \times 10^{-5}-7 \times 10^{-3}$ \\
\hline 6-BIO (1) & $-8,2$ & 1,7 & 1,5 \\
\hline $\mathrm{SB} 216763(\mathrm{~m})$ & $-8,6$ & 0,9 & 0,34 \\
\hline Hymedialsine (o) & $-6,3$ & 36.2 & 0,01 \\
\hline AR A014418 (p) & $-6,9$ & 13,7 & 0,14 \\
\hline
\end{tabular}

Fonte: Adaptado de ELDAR-FINKELMAN e MARTINEZ, 2011.

A constante de inibição (Ki), assim como a energia de docagem, prediz informações sobre a establidade do complexo receptor-ligante formado, quanto menor $\mathrm{Ki}$, maior a estabilidade do complexo e consequentemente, maior a eficácia do ligante em inibir o receptor. A tabela 1 mostra que os três ligantes que apresentaram menor energia de docagem e Ki foram as moléculas Alsterpaullone, Kenpaullone e SB216763. Na tabela 1 também é mostrado que o $\mathrm{IC}_{50}$ dos ligantes em questão, são inferiores ao do lítio. No gráfico de barras, Gráfico 1, são analisadas e comparadas, de forma mais ampla, as energias de docagem molecular de todos os ligantes na GSK-3 $\beta$. Este resultado mostra que, quanto menor a energia de docagem molecular, mais forte e o processo de inibição da enzima, ou seja, os ligantes que apresentaram energia entre $-8 \mathrm{kcal} / \mathrm{mol} \mathrm{e}-9 \mathrm{kcal} / \mathrm{mol}$, foram os melhores. 


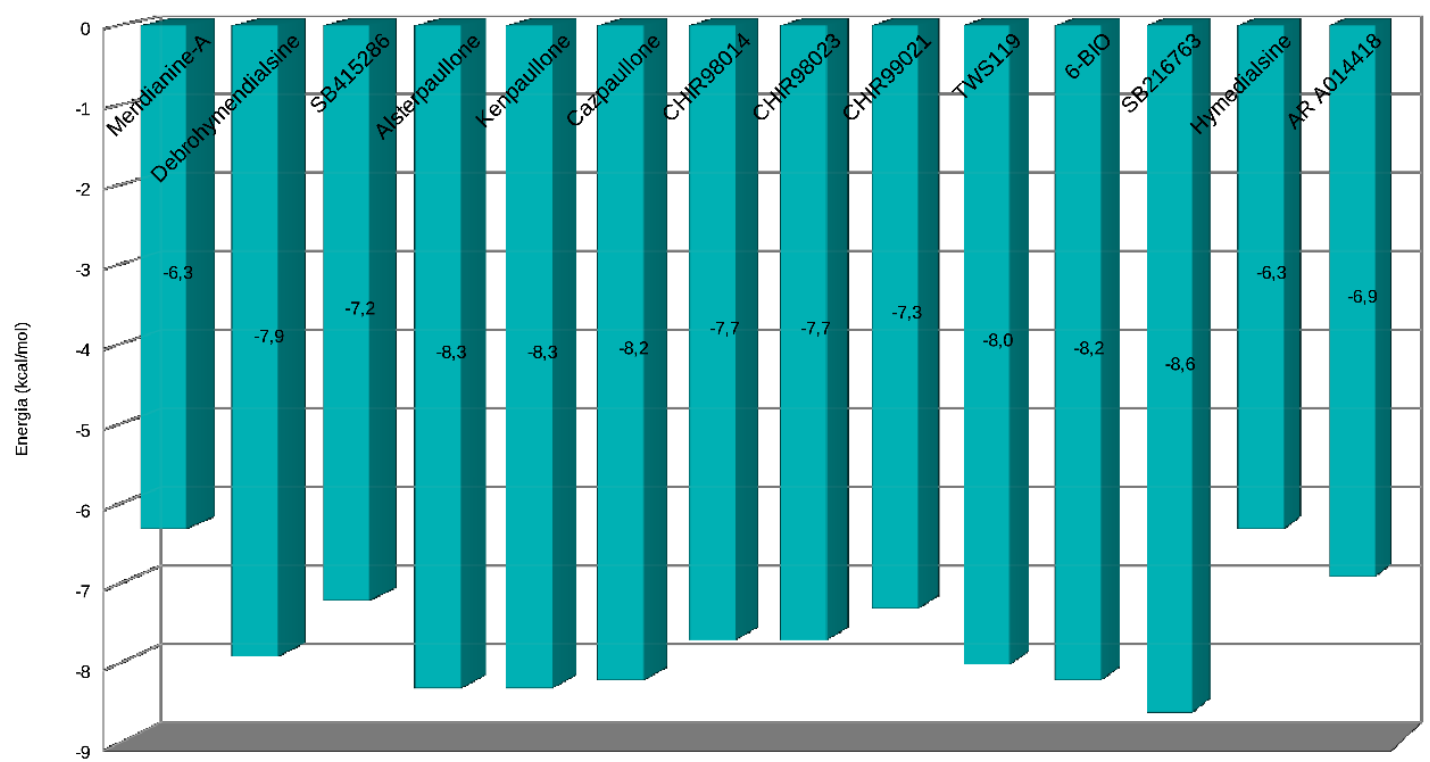

Gráfico 1 - Gráfico de barras da energia de ligação dos ligantes

Para uma maior análise das interações realizadas entre a enzima e os ligantes no processo de docagem molecular, a tabela abaixo traz a sequência de aminoácidos (A.A) do modelo cristalográfico da GSK-3 $\beta$ e todas as interações realizadas entre os ligantes:

Tabela 2 - Mapeamento da Interação dos ligantes com os aminoácidos da GSK-3ß.

\begin{tabular}{|c|c|c|c|c|c|c|c|c|c|c|c|c|c|c|c|}
\hline A.A. & & & & & & & & Liga & & & & & & & \\
\hline & (a) & (b) & (c) & (d) & (e) & (f) & (g) & (h) & (i) & (j) & (I) & (m) & (n) & (o) & (p) \\
\hline Ile62 & $\mathbf{X}$ & & $\mathbf{X}$ & $\mathbf{X}$ & $\mathbf{X}$ & $\mathbf{X}$ & $\mathbf{X}$ & $X$ & & $\mathbf{X}$ & $\mathbf{X}$ & $\mathbf{X}$ & $\mathbf{X}$ & & \\
\hline Gly63 & & & & & & & & & $\mathbf{X}$ & & & & & & \\
\hline Phe67 & & $\mathbf{X}$ & & $\mathbf{X}$ & $\mathbf{X}$ & $\mathbf{X}$ & $\mathbf{X}$ & $\mathbf{X}$ & $\mathbf{X}$ & $\mathbf{X}$ & $\mathbf{X}$ & & $\mathbf{X}$ & & \\
\hline Val70 & $\mathbf{X}$ & $\mathbf{X}$ & $\mathbf{X}$ & $\mathbf{X}$ & $\mathbf{X}$ & $X$ & $\mathbf{X}$ & $\mathbf{X}$ & $\mathbf{X}$ & $\mathbf{X}$ & $\mathbf{X}$ & $\mathbf{X}$ & $\mathbf{X}$ & & \\
\hline Ala83 & $\mathbf{X}$ & & $\mathbf{X}$ & & & & & $\mathbf{X}$ & & $\mathbf{X}$ & & $\mathbf{X}$ & $\mathbf{X}$ & & \\
\hline Lys85 & $\mathbf{X}$ & $\mathbf{X}$ & $\mathbf{X}$ & $\mathbf{X}$ & $\mathbf{X}$ & $\mathbf{X}$ & $\mathbf{X}$ & $\mathbf{X}$ & $\mathbf{X}$ & $\mathbf{X}$ & & $\mathbf{X}$ & & & \\
\hline Glu97 & & & & & & & & & $\mathbf{X}$ & & & & & & \\
\hline Val110 & & $\mathbf{X}$ & $\mathbf{X}$ & & & & & & & & & & & & \\
\hline Leu132 & $\mathbf{X}$ & $\mathbf{X}$ & & $\mathbf{X}$ & $\mathbf{X}$ & $\mathbf{X}$ & $\mathbf{X}$ & & $\mathbf{X}$ & $\mathbf{X}$ & $\mathbf{X}$ & & & & \\
\hline Asp133 & $\mathbf{X}$ & $\mathbf{X}$ & $\mathbf{X}$ & $\mathbf{X}$ & $\mathbf{X}$ & $\mathbf{X}$ & & & & $\mathbf{X}$ & & $\mathrm{X}^{*}$ & & & \\
\hline Tyr134 & $\mathbf{X}$ & $\mathbf{X}$ & $\mathbf{X}$ & & & & $\mathbf{X}$ & $\mathbf{X}$ & $\mathbf{X}$ & $\mathbf{X}$ & $\mathbf{X}$ & $\mathbf{X}$ & & & \\
\hline Val135 & & $X^{*}$ & $X^{*}$ & & & & & & $\mathbf{X}$ & $\mathbf{X}^{*}$ & $\mathbf{X}$ & $X^{*}$ & & & \\
\hline Pro136 & & & & & & & $\mathbf{X}$ & $\mathbf{X}$ & $\mathbf{X}^{*}$ & & $\mathbf{X}$ & & & & \\
\hline Thr138 & & & & & & & $X$ & $\mathbf{X}$ & $\mathbf{X}$ & & & & & & \\
\hline Tyr140 & & & & & & & $\mathbf{X}$ & & & & & & & & \\
\hline Arg141 & & & & & & & $\mathbf{X}$ & & $\mathbf{X}$ & & & & & & \\
\hline Ala170 & & & & & & & & & & & & & & $\mathbf{X}$ & $\mathbf{X}$ \\
\hline His 173 & & & & & & & & & & & & & & $\mathbf{X}$ & $\mathbf{X}$ \\
\hline
\end{tabular}




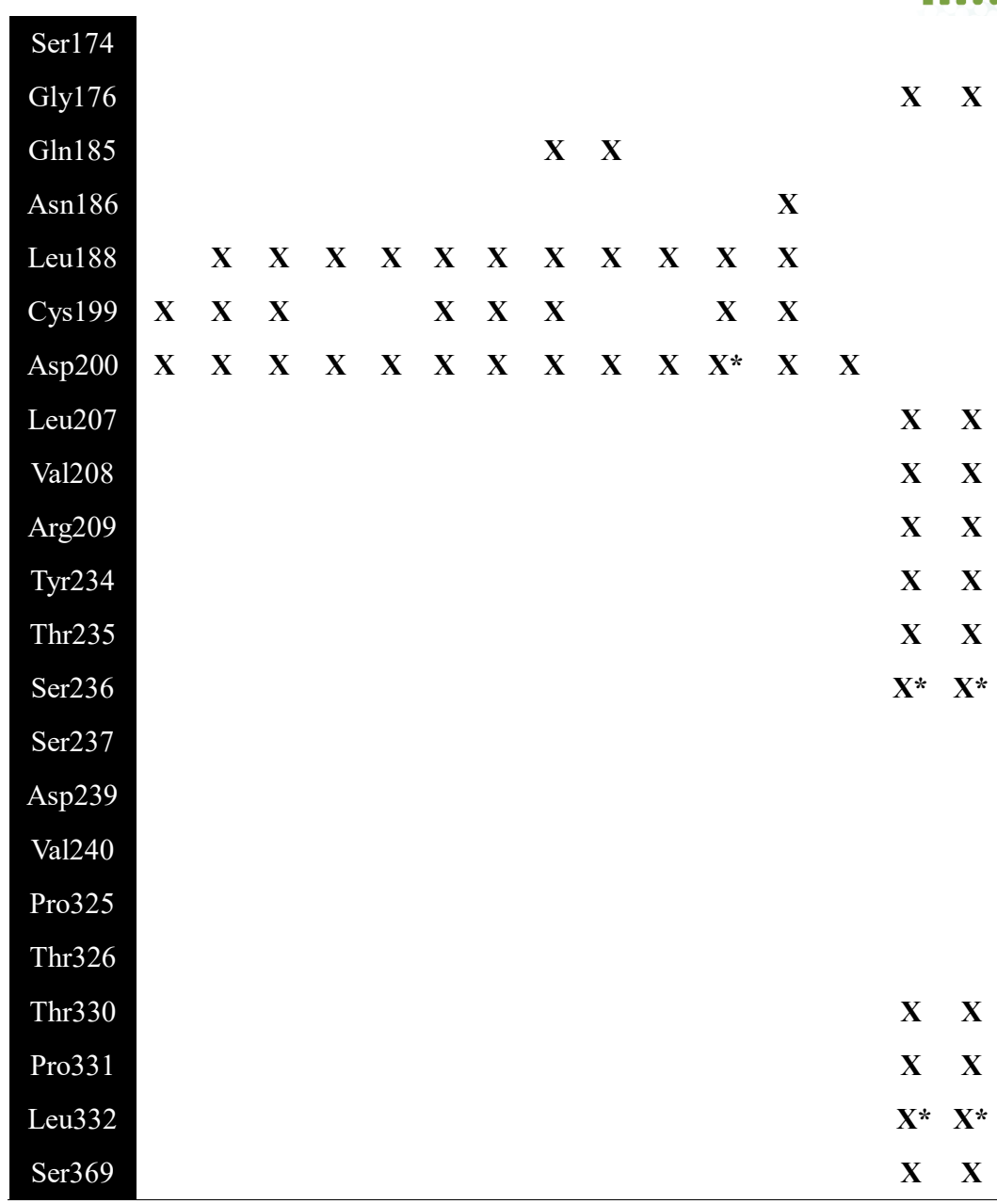

Fonte: O próprio autor

$\mathrm{Na}$ tabela 2, os ligantes estão representados por letras do alfabeto, da letra 'a' a 'o' de acordo com a tabela 1. Ainda na tabela 2, o 'X' com um asterisco representa uma interação eletrostática entre o aminoácido e o ligante, e os demais representam interações mais fracas, de van Der Waals. O gráfico 2 mostra a frequência em que um determinado aminoácido da GSK-3 $\beta$ interage com algum dos ligante. 


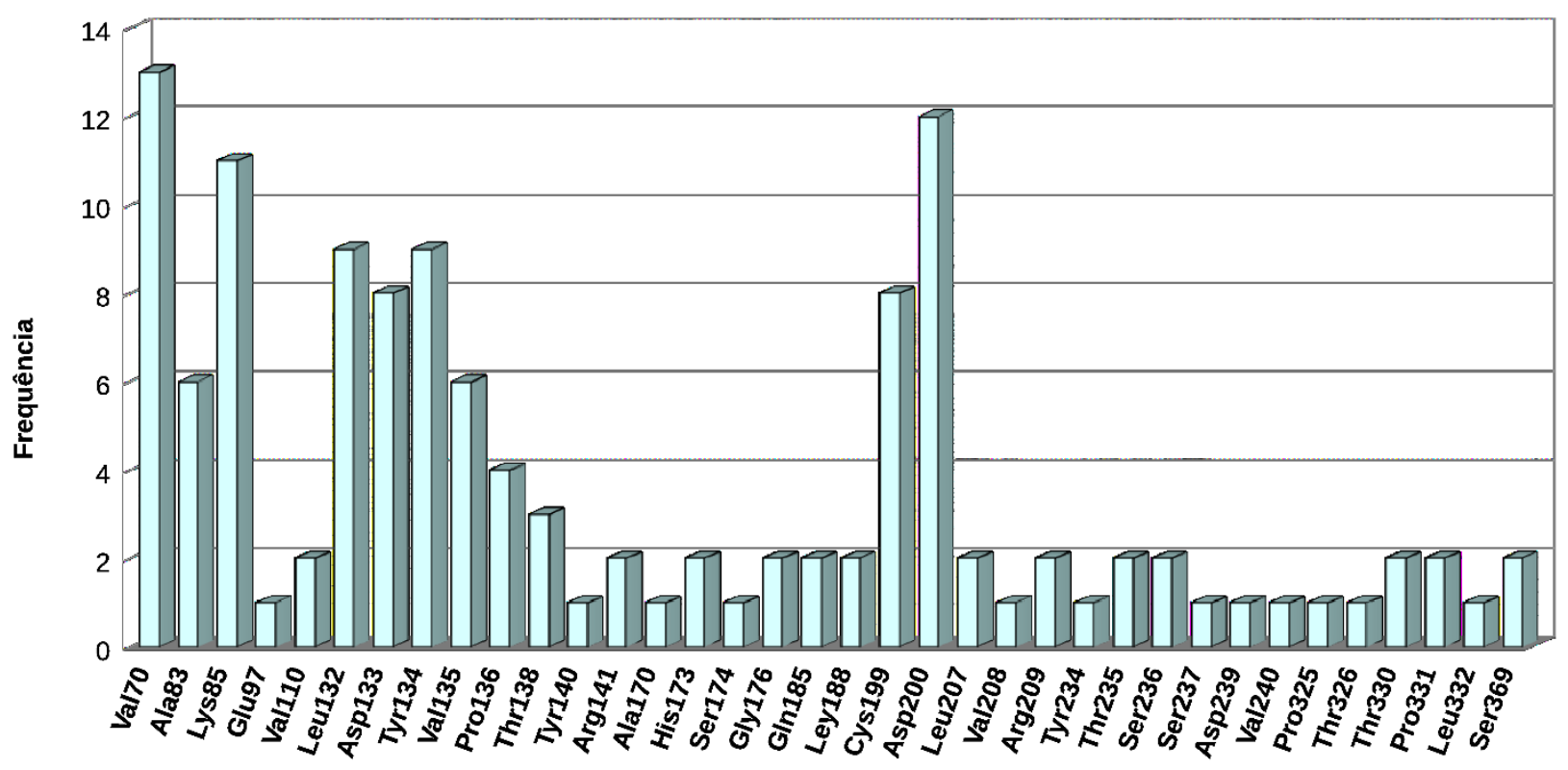

Aminoácido

Gráfico 2 - Frequência de interação dos ligantes com os aminoácidos da GSK-3ß.

Os demais ligantes realizam pelo menos uma interação com algum aminoácido da GSK-3 $\beta$. Alguns dos aminoácidos mostram-se mais propensos a interagirem com os ligantes como mostra o gráfico de frequência abaixo:

O ligante AR A014418 (o), apesar de não apresentar um valor de energia de docagem tão satisfatório tanto quanto outros ligantes, realiza duas interações eletrostáticas entre os aminoácidos Leu332 e Ser336 da enzima. Essas interações são interações mais fortes (estáveis) que as interações de apolares (interações de van Der Waals).

O ligante de melhor desempenho, SB216763 (m), também realiza duas interações eletrostáticas, com os aminoácidos Asp133 e Val135, além de dez interações de van Der Waals, como mostra a Figura 6: 


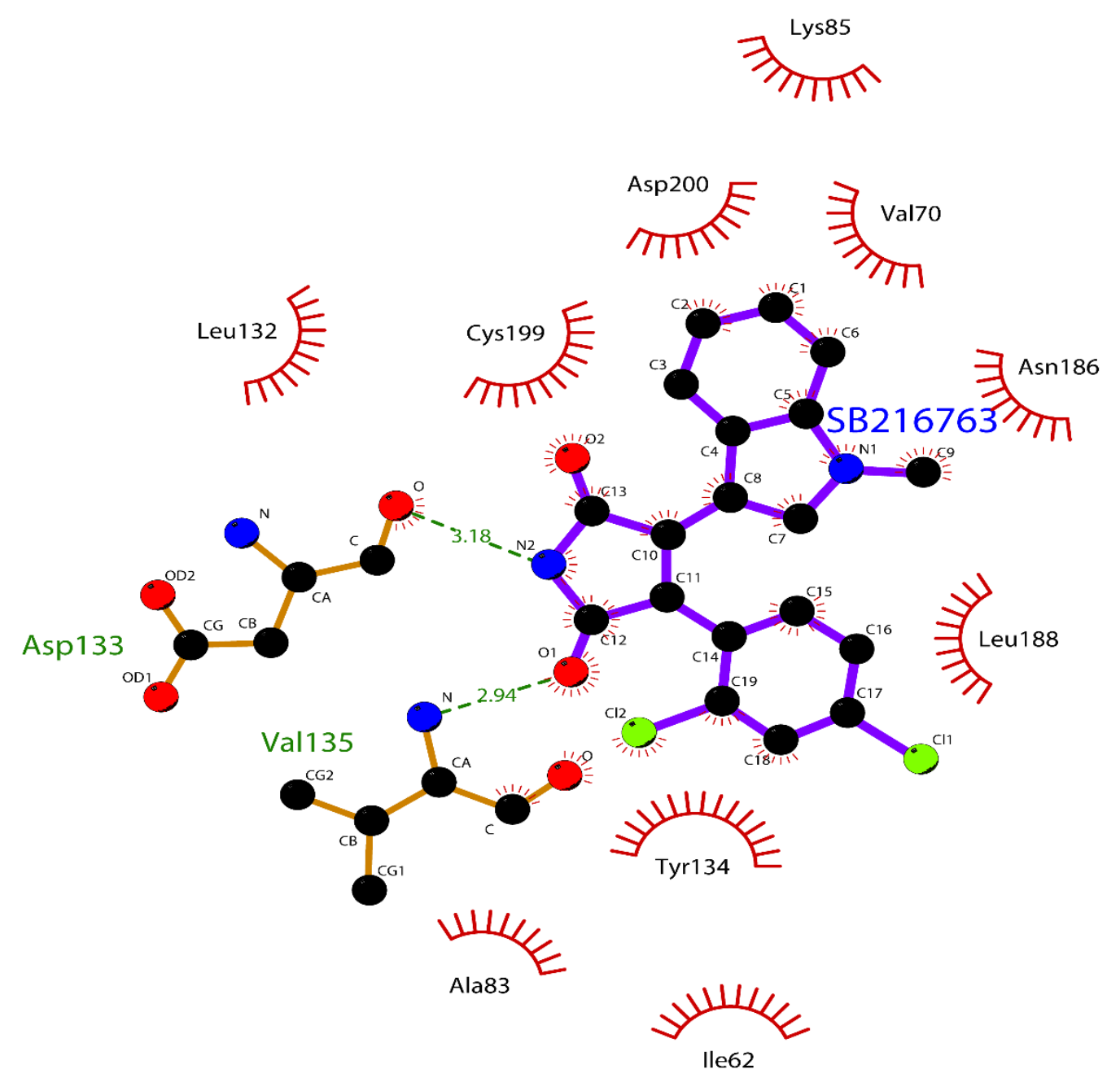

Figura 6 - Representação do ligante SB216763 e os aminoácidos em que o mesmo interage.

Assim como na tabela 2, os aminoácidos de interação da enzima estão sequenciados no Gráfico 2. Os picos do gráfico mostram a frequência de interação entre determinado aminoácido e os demais ligantes. Os cinco maiores picos, são respetivamente, os aminoácidos (Ile62), (Phe67), (Val70), (Lys85) e (Asp200). Destes aminoácidos mencionados, três deles fazem parte do grupo dos sete aminoácidos (Phe67, Lys85, Glu97, Arg141, Gln185, Asp200 e Arg220) que compõe a região da GSK$3 \beta$ que interagem com os ligantes competitivos com ATP, segundo a literatura.

Dos ligantes testados na simulação computacional, sete deles realizaram uma interação eletrostática com a enzima, e dois deles (SB216763 e SB415286), duas interações. Os aminoácidos que mais aparecem nessas interações são Asp200, Leu85, Asp133, Val135. De todos os ligantes, os que apresentaram melhor energia de ligação em relação à GSK-3 $\beta$, e consequentemente menor valor de $\mathrm{Ki}$ foram SB216763, com Ki e energia de ligação respectivamente 0,9 e $\quad-8,6$ $\mathrm{kcal} / \mathrm{mol}$, e os ligantes Alsterpaullone e Kenpaullone, ambos com Ki igual a 1,4 e energia de ligação igual a $-8,3$ $\mathrm{kcal} / \mathrm{mol}$. 


\section{CONCLUSÕES}

Através da docagem molecular, foi possível analisar quais dos ligantes em estudos apresentou uma melhor afinidade pelo receptor, mostrando quais deles apresenta uma maior eficiência em inibir in silico a GSK-3 $\beta$, além do estudo das principais interações realizadas no complexo receptor-ligante formado. Apesar de o sítio catalítico descrito na literatura não incidir perfeitamente com a simulação, pode-se dizer que os ligantes em estudo

\section{CONSIDERAÇÕES FINAIS (apenas}

\section{quando houver)}

As análises de energia de docking e de interação receptor-ligantes efetuadas podem, com o refinamento da pesquisa,

\section{AGRADECIMENTOS}

Os autores agradecem à FAPES, ao IFES e ao CNPq pelo suporte financeiro e

\section{REFERÊNCIAS}

APHAHAMIAN, I. Análise da função renal em idosos com comprometimento cognitivo leve usuários de lítio em baixa dosagem: um estudo randomizado, duplo cego, placebo controlado. Tese (Doutorado em Ciência) - Faculdade de Medicina, Universidade de São Paulo, 2013.

CASTRO-COSTA, E.; SILVA, A. G; A adesão terapêutica no transtorno bipolar. Debates em psicologia. Rio de Janeiro, $n$. 5, p. 8-11, 2011.

DEL PORTO, J. A; Versiani, M. Transtorno bipolar: tratando o episódio agudo e planejando a manutenção. J Bras Psiquiatr. 54(2): p. 84-88, 2005. interagiram com boa parte dos aminoácidos descritos em tal sítio catalítico. Ao todo, nove dos quatorze ligantes realizaram pelo menos uma interação eletrostática com a enzima. SB216763, Kenpaullone e Alsterpaullone foram os inibidores que apresentaram melhor potencial em inibir in silico a enzima, apresentando os menores valores de $\mathrm{Ki}$ entre as demais moléculas testadas sugerindo um potencial de inibição superior ao do lítio.

possibilitar o planejamento de fármacos que ajam com maior eficácia ao inibir a GSK-3 $\beta$ e que possuam menor toxicidade ao organismo, melhorando a qualidade de vida do portador do transtorno bipolar do humor.

pelos recursos computacionais necessários para o desenvolvimento deste trabalho.

DHANIK, A. KAVRAKI, L. E. Proteinligand interactions: Computational docking. ELS. 2012.

ELDAR-FINKELMAN, H. Glycogen synthase kinase-3: an emerging therapeutic target. Trends Mol. Med. v.8, p.126-132, 2002.

ELDAR-FINKELMAN, H.; MARTINEZ, A.; GSK-3 inhibitors: preclinical and clinical focus on CNS. Frontiers in molecular neuroscience. v. 11, 2011.

HASSINEN, T.; PERÄKYLÄ, M. New energy terms for reduced protein models implemented in an off-lattice force field. $\mathbf{J}$ Comput Chem. v.22, p.1229-1242, 2001. 
KLEIN, Peter S.; MELTON, Douglas A. A molecular mechanismo for the effect of lithium on development. PNAS. Estados Unidos, v.93, p.8455-8459, 1996.

OLIVEIRA, J. L., SILVA JÚNIOR, G. B., ABREU, K. L. S., ROCHA, N. A., FRANCO, L. F. L. G., ARAÚJO, S. M. H. A., DAHER, E. F. Nefrotoxidade por lítio. Rev Assoc Med Bras. Ceará, v.56, p.6006, 2010.

PIETRALONGA, T. C., GONÇALVES, A. S. GONÇALVES, S. Q. B., FRANÇA, T. C. C. Estudo computacional de reativadores da acetilcolinesterase inibida pelo pesticida agrícola fenamifós. Ifes Ciência. Espirito Santo, v. 1, n. 2, 2015.

ROSA, A.R.; KAPCZINSKI, F.; OLIVA, R.; STEIN, A.; BARROS, H.M.T. Monitoramento da adesão ao tratamento com lítio. Rev Psiq Clín. 33 (5); p. 249-261, 2006.

STEWART, J. J. Optimization of parameters for semiempirical methods V: Modification of NDDO approximations and application to 70 elements. J Mol Model. v.13, p.11731213, 2007. 